\title{
Mobile Phone Keeping Behavior among Working Women
}

\author{
Devi R. Nithiya ${ }^{1}$, Arun Tipandjan ${ }^{2}$, Sadhanandham Shrinuvasan ${ }^{3}$, \\ Vivekanandan Ravichandran ${ }^{4}$, Kavitha Durairaj ${ }^{5}$, Kannan Ragavan ${ }^{6}$ \\ ${ }^{l}$ Assistant Professor, Department of Physiology, Mahatma Gandhi Medical College and Research Institute, Sri \\ Balaji Vidyapeth (Deemed to be), Pillayarkuppam, Puducherry, ${ }^{2}$ Research Psychologist, International Centre \\ for Psychological Counseling and Social Research Puducherry, ${ }^{3}$ Assistant Professor, Department of Radiology \\ and Imaging Sciences, Indira Gandhi Medical College and Research Institute, Puducherry, ${ }^{4}$ Specialist Grade-I, \\ Department of Radiology and Imaging Sciences, Indira Gandhi Government General Hospital and Post Graduate \\ Institute, Puducherry, ${ }^{5}$ Associate Professor, Department of Obstetrics and Gynecology, College of Nursing, Mother \\ Theresa Post graduate and Research Institute of Health Sciences, Puducherry, ${ }^{6}$ Assistant Professor, Department \\ of Radiography, College of Medical Radiology and Imaging Technology, Mother Theresa Post graduate and \\ Research Institute of Health Sciences, Puducherry
}

\begin{abstract}
Background: Recent alarming increase in breast cancer, especially in younger women, has been attributed to the increasing usage of mobile cellular phones and their placement in contact with the body especially the breast region. The bio-effects of high frequency electromagnetic radiations accompanied by thermal damage to the tissues play an important role in tumor initiation and progression.
\end{abstract}

Method: The study was carried out in 260 working women from Pondicherry. They were questioned about mobile phone keeping behavior using a three item questionnaire.

Results: Women involved in unskilled job kept their mobile phones more proximal to the breast region when compared to the women engaged in white collar job. However the duration of mobile phone usage was higher in the latter group.

Conclusion: Longitudinal studies to follow up the relationship between mobile phone keeping behavior and development of breast cancer need to be undertaken. Hence we propose researchers to ask for history about mobile phone keeping behavior while dealing with breast cancer patients.

Keywords: Breast, cancer, cellphone, keeping behavior, mobile phone.

\section{Introduction}

Globally mobile phone usage among the younger generation has increased drastically over the recent past with the number of subscribers crossing 725 million. ${ }^{1}$

\footnotetext{
Corresponding Author:

Devi R. Nithiya,

Assistant Professor, Mahatma Gandhi Medical College and Research Institute, Sri Balaji Vidapeeth (Deemed to be university), Pillayarkuppam, Puducherry

e-mail: nithiya.ravi@gmail.com
}

Radiowave and microwave radiations of frequency ranging between $0.1-300,000 \mathrm{MHz}$ are used in radio communication, radio location centers and cellular phones. ${ }^{2}$ Electromagnetic radiation from mobile cellular phones draw immense attention and its contribution as an environmental factor in the development of various health issues including breast cancer in young women is still a debatable issue. Some studies claim the direct thermal energy emitted from mobile phones to be the cause while a few other studies have reported non- thermal biological effects due to electromagnetic radiations to be responsible for the disease pathogenesis. ${ }^{3}$ Electromagnetic radiations emitted from mobile phones during signal transmission are generally high frequency 
radiowaves. Extremely low frequency electromagnetic waves, emitted during battery discharge that occurs merely when the device power is switched on, may also be involved in carcinogenesis. ${ }^{4}$

Understanding environmental and behavioral risk factors play an important role in identifying and preventing the increase in disease incidence. One such factor of concern is the increasing usage of mobile cellular phones and their placement in contact with the body especially the breast region. ${ }^{3}$ Breast cancer hits third in the list of common cancers worldwide. India along with China and United States contributes to about one- third of the global breast cancer disease burden. ${ }^{5}$ There exists a lacuna in the awareness of risk factors for developing breast cancer among the public. In most instances disease in young women less than 40 years of age seems to carry a genetic predisposition with positive family history of breast cancer. Sporadic occurrence of breast cancer is common among women in the post- menopausal age group without any family history. of late there appears a rise in the number of breast cancer cases under 40 years of age in the absence of family history. ${ }^{6}$ There has been over emphasis on the genetic factors causing breast cancer; however in reality, environmental and lifestyle factors do play a considerable and huge role in cancer pathogenesis. Even a small increase in the incidence of cancer due to mobile phone usage would be considered an issue of significant public health importance. ${ }^{4}$

In India, most women culturally prefer to wear saree (a traditional dress) especially those working in fields or construction works. They are more prone to slip their mobile phones into their blouse. There exists a lacuna among Indian studies that explore the effect of keeping mobile phones in proximity to the breast region and the effects of electromagnetic radiations as a possible risk factor in the development of breast cancer.

\section{Aims and Objectives:}

1. To compare the difference in body region in contact with mobile phones between women engaged inwhite collar jobs and women engaged in unskilled jobs

2. To compare the duration of mobile phone usage between women engaged in white collar jobs and women engaged in unskilled jobs

3. To compare the duration of keeping mobile phone in contact with the body parts among women engaged in white collar jobs and women engaged in unskilled jobs

\section{Materials and Method}

The study was conducted in Puducherry, India, an old French territory between May 2019 and January 2020. The study was designed as across sectional comparative study among 260 women included from both urban and rural population. Women who possessed a mobile phone with them were recruited for the study using snow ball sampling technique. An informed consent was obtained from the participants in vernacular language.

Questionnaire: Those women who consented to participate in the study were administered a simple 3 item questionnaire to provide information regarding mobile phone keeping behavior and usage duration. The following items were presented in English/Local vernacular language (Tamil) based on the participant's choice.

(i) In which region of your body do you keep your mobile phone when not using it for talking or texting or browsing?

(ii) How many minutes in a day do you use your mobile phone for talking or texting or browsing?

(iii) How many minutes in a day do you keep your mobile phone in contact with your body?

Statistical analysis: The categorical data were described as frequency and percentage [item (i)]. The data obtained as minutes per day was described as mean $\pm \mathrm{SD}$ and comparison between groups were done using unparied t- test [items (ii) and (iii)].

\section{Results}

The mean age of women who participated in this study was 38.58 years. The women who were engaged in white collared jobs such as teaching, health care, clerical jobs reported that they keep their mobile phones in hand while not using it (53.4\%), in contrast, the women engaged in unskilled jobs such as construction site workers, house maids and agricultural laborers slip their mobile phones in their blouses, near their breast (50\%); and hip region $(24.3 \%)$. Apart from the above mentioned body regions $41.4 \%$ women engaged in white collar job and $43.6 \%$ of women engaged in unskilled job reported that they keep their mobile phone in contact with the other regions of the body (Table 1). 
Table 1: Frequency and percentage distribution of body region in contact with mobile phone while not using it

\begin{tabular}{|l|c|c|c|c|}
\hline \multirow{2}{*}{$\begin{array}{l}\text { Body region in contact } \\
\text { with mobile phone }\end{array}$} & \multicolumn{4}{|c|}{ Type of work } \\
\cline { 2 - 5 } & White collared job (n=116) & \multicolumn{2}{c|}{ Unskilled job (n=144) } \\
\cline { 2 - 5 } & Frequency & Percentage & Frequency & 2.1 \\
\hline Hands & 62 & 53.4 & 3 & 35 \\
\hline Hip & 5 & 4.3 & 72 & 24.3 \\
\hline Near Breast & 1 & 0.9 & 34 & 50.0 \\
\hline Others & 48 & 41.4 & & \\
\hline
\end{tabular}

When comparing the duration of mobile phone usage between white collared and unskilled workers, the former were found to use their mobile phones for 92.37 min per day while the latter used only $15.53 \mathrm{~min}$ per day. There was a statistically significant difference $(\mathrm{p}<0.001)$ found in the duration of mobile phone usage between the two groups (Table 2).
When the participants were asked "How long you keep your mobile phones with you while not using it?" women engaged in white collared job responded they keep about 495 min ( 8 hours) while unskilled workers keep their mobile phones for 327.52 min ( 5.5 hours). There was a statistically significant difference in duration of keeping the mobile phone with them $(\mathrm{p}<0.001)$.

Table 2: Comparison of duration of mobile phone usage and duration of mobile phone keeping among study participants

\begin{tabular}{|c|c|c|c|c|}
\hline Variable (min/day) & Groups & $\mathbf{N}$ & Mean \pm SD & p value \\
\hline \multirow{2}{*}{ Mobile Phone usage } & White collared job & 116 & $92.37 \pm 30.97$ & \multirow{2}{*}{$0.000 * *$} \\
\hline & Unskilled job & 144 & $15.63 \pm 13.46$ & \\
\hline \multirow{2}{*}{ Mobile Phone keeping } & White collared job & 116 & $495.00 \pm 50.59$ & \multirow{2}{*}{$0.000^{* *}$} \\
\hline & Unskilled job & 144 & $327.92 \pm 66.53$ & \\
\hline
\end{tabular}

\section{Discussion}

The concern about mobile phone being involved in carcinogensis is due to two reasons. One is the electromagnetic radiations emitted due to signal transmission and the other is thermogenic effect produced by the device. The cellphones with $2 \mathrm{G}$ support emit electromagnetic radiations in the range of 890-960 for Global system for mobile communications (GSM). ${ }^{7}$ $3 \mathrm{G} / 4 \mathrm{G}$ supported mobile phones tend to emit higher EMR. Biological stress responses to these radiations have become an important public health concern.

The result of this study revealed that women engaged in white collar jobs preferred to keep their mobile phone proximal to hand and other regions. On the other hand, women who were engaged in unskilled job preferred to keep their mobile near their breast and hip without knowing the fact that proximity of cellphones to the body and their contact with breast tissue especially in young girls probably carry a highrisk of tumourogenesis.

Human breast cancer cells when exposed to electromagnetic frequencies under laboratory conditions grow faster when compared to low environmental exposure. ${ }^{3}$ As per WHO/ICNIRP Environmental Health Criteria (1993) non- thermal intensity of microwaves can be considered to have weak biological influence. ${ }^{8}$ The international expert panel of IARC (International Agency for Research on Cancer in Lyon) concluded that non- thermal radiofrequency exposure is a possible 
carcinogen (group 2B) for humans. ${ }^{9}$ Bio-effects of high frequency EMR are accompanied by thermal damage to the tissues. ${ }^{4}$ Non- ionized electromagnetic radiations induced oxidative stress due to imbalance in free radical production and antioxidant protective mechanisms cause cell damage and apoptosis. Kahya et al observed a rise in cytosolic reactive free radicals accompanied by increase in enzyme caspases levels that are pro- apoptotic in breast cancer cell lines exposed to $900 \mathrm{MHz}$ radiations. However the mechanism of EMR induced biological cell response is yet to be uncovered. ${ }^{10}$

Mobile phones produce local heating effect emitting a total peak output power of about 2 watt contributing to an average specific absorption rate (SAR) of $2.0 \mathrm{~W} /$ $\mathrm{Kg}$. SAR is a measure of rate of energy absorbed by the human body when exposed to a radio frequency (RF) electromagnetic field. ${ }^{11}$ Distribution of radio- frequency energy and SAR is non- homogenous inside the body for different organs and tissues leading to difference in propensity to develop DNA damage causing cancer. Moreover the absorption of EMR is proportional to the heat generated at the interphase of biological tissue in contact with mobile phone. ${ }^{4}$ This study also revealed that the duration of mobile use was different between white collared working women and women engaged in unskilled job hinting that white coloured women are more vulnerable to the ill effect of mobile phone. The duration of keeping mobile phone with them also showed that there was significant difference between two groups studied, white collared women carry the mobile phone with them for longer duration when compared to women engaged in unskilled job. A few studies concluded that mobile phone usage though likely to produces deleterious biological response, do not demonstrate statistical significant harmful changes. ${ }^{12,13}$ Though the biological responses largely depend on the duration and frequency of exposure to EMR emitted from mobile phones, inter- individual variations do occur commonly. Safety guidelines and regulations for exposure of wireless communication devices including mobile phones are fixed based on their thermal bioeffects, not considering non- thermal effects of electromagnetic radiations. Existing public safety standards remain unmatched with the adverse health outcomes due to radiofrequency radiations from mobile phones. Attempts to assess adverse outcomes from EMR lower than the existing public exposure safety limits need to be undertaken to prevent future health risks especially cancer. Curtailing the exposure to excessive handling and usage of mobile phones should be considered as a vital initial step towards reducing the risk of developing cancer and other health hazards. Cumulative absorption of electromagnetic energy depends greatly upon the cumulative hours of usage of mobile phones. ${ }^{4} \mathrm{~A}$ few investigators also expressed their opinion that EMR play a role in tumor initiation and progression. Tumor progression is aided by increase in tumor growth rate and inhibition of involution. ${ }^{14,15}$

Controversies in the results obtained from previous studies however need to be addressed due to the short study period and recall bias among the participants. Mobile phones are relatively a new technology and demands future studies on long term exposure before conclusions can be drawn on their tumorogenic effect in humans. The long induction and latency period of carcinogenesis raises concern on accuracy of association between mobile phone usage and development of cancer. $^{16}$

\section{Future Persepectives:}

Many of the studies conducted in the past focus on the development of brain cancer with little emphasis of breast cancer and testicular cancer. Future studies should be designed to study the bioeffects of EMR on infertility and risk for developing breast cancer

The urgent need for the present Indian scenario is preventive approach in the form of health information programs to promote safe usage of mobile phones even though the 10 years studies do not reveal any significant carcinogenetic effect. ${ }^{17}$ This study is an eye opener intends to provide researchers in breast cancer to include mobile phone keeping behavior as a possible environmental risk factor in the development of breast cancer. Considering the long latency prior to overt appearance of cancer, immature conclusions that electromagnetic radiations from mobile cellular phones are not involved in breast cancer pathogenesis should be discarded. As retrospective studies may be accompanied by patient and interviewer bias to a larger extent, longitudinal studies should be undertaken to prove or disprove the association. Administration of health education to instill awareness among the public regarding hazards of excessive mobile phone usage and its contact with their body surface occupies prime importance.

Limitations of the Study: Details of the network $2 \mathrm{G} / 3 \mathrm{G} / 4 \mathrm{G}$ and the type of mobile phone were not questioned. 
Ethical Clearance: Ethical clearance for the conduct of study was obtained from International center for psychological counseling and social research, Puducherry.

\section{Source of Funding: Nil}

\section{Conflict of Interest: Nil}

\section{References}

1. Meena JK, Verma A, Kohli C, Ingle GK. Mobile phone use and possible cancer risk: Current perspectives in India. Indian journal of occupational and environmental medicine. 2016 Jan;20(1):5.

2. Szmigielski S. Cancer risks related to lowlevel RF/MW exposures, including cell phones. Electromagnetic biology and medicine. 2013 Sep 1;32(3):273-80.

3. Hardell L, Sage C. Biological effects from electromagnetic field exposure and public exposure standards. Biomedicine \& pharmacotherapy. 2008 Feb 29;62(2):104-9.

4. Kundi M. The Controversy about a possible relationship between mobile phone use and cancer. Environmental health perspectives. 2009 Mar; 117(3): 316- 24.

5. Statistics of Breast Cancer in India [Internet]. WHO 2012 [cited 2017 Oct 21]. Available from: http:// www.breastcancerindia.net/statistics/stat_global. html.

6. Redmayne M. Where's Your Phone? A Survey of where women aged 15-40 carry their smartphone and related risk perception: A survey and pilot study. PLoS ONE 2017;12(1): e0167996. doi:10.1371/ journal.pone.0167996

7. Valberg PA, Van Deventer TE, Repacholi MH. Workgroup report: base stations and wireless networks-radiofrequency (RF) exposures and health consequences. Environmental health perspectives. 2007 Mar;115(3):416.

8. WHO/INIRC (1993). Electromagnetic fields (300 $\mathrm{Hz}-300 \mathrm{GHz}$ ). Environmental health criteria No. 137, Geneva: WHO

9. IARC classifies radiofrequency electromagnetic fields as possibly carcinogenic to humans Lyon,
France, 2011 May 31[cited 2017 Oct 10]-The WHO/International Agency for Research on Cancer (IARC). Available from: http://www.iarc. fr/en/media-centre/pr/2011/pdfs/pr208_E.pdf.

10. Kahya MC, Nazıroğlu M, Çiğ B. Selenium reduces mobile phone $(900 \mathrm{MHz})$-induced oxidative stress, mitochondrial function, and apoptosis in breast cancer cells. Biological trace element research. 2014 Aug 1;160(2):285-93.

11. Sage C. Bioinitiative report 2012 [Internet]. [2014 updated cited 2017 Oct 23]. Available from:http:// www.bioinitiative.org/report/wp-content/uploads/ pdfs/sec01_2012_summary_for_public.pdf

12. Guney M, Ozguner F, Oral B, Karahan N, Mungan T. $900 \mathrm{MHz}$ radiofrequency-induced histopathologic changes and oxidative stress in rat endometrium: protection by vitamins $\mathrm{E}$ and $\mathrm{C}$. Toxicology and industrial health. 2007 Aug; 23(7):411-20.

13. Volkow ND, Tomasi D, Wang GJ, Vaska P, Fowler JS, Telang F, Alexoff D, Logan J, Wong C. Effects of cell phone radiofrequency signal exposure on brain glucose metabolism. Jama. 2011 Feb 23;305(8):808-13.

14. Johansen C, BoiceJr JD, McLaughlin JK, Olsen JH. Cellular telephones and cancer - a nationwide cohort study in Denmark. Journal of the National Cancer Institute. 2001 Feb 7;93(3):203-7.

15. Muscat JE, Malkin MG, Thompson S, Shore RE, Stellman SD, McRee D, Neugut AI, Wynder EL. Handheld cellular telephone use and risk of brain cancer. Jama. 2000 Dec 020;284(23):3001-7.

16. Ahlbom A, Feychting M, Green A, Kheifets L, Savitz DA, Swerdlow AJ, ICNIRP (International Commission for Non-Ionizing Radiation Protection) Standing Committee on Epidemiology. Epidemiologic evidence on mobile phones and tumor risk: a review. Epidemiology. 2009 Sep 1;20(5):639-52.

17. Interphone Study Group. Brain tumour risk in relation to mobile telephone use: results of the Interphone international case-control study. International journal of epidemiology. 2010 May $17 ; 39(3)$ 